\title{
The Political Economy of Nursing Homes
}

\author{
By MaRY Adelaide Mendelson and David Hapgood
}

ABSTRACT: The nursing home industry receives threequarters of its income from government. The industry earns high profits while providing poor patient care. Considerable swindling of government funds occurs. One category is nickel and diming, which consists of clipping every possible dollar from government money as it passes through nursing home accounts. Another method-large scale and often within the law-involves the manipulation of ownership and mortgages. There are several causes for the failure of government to control nursing home swindles. While there is no lack of regulations, the will to enforce them is lacking. Industry lobbyists are especially influential at the state level, where the Medicaid rate is set. The federal government has failed to collect basic information about the industry and denies the public ready access to the reports on nursing home inspections. The industry's immunity from regulation, in large part, results from the lack of countervailing pressure from the public.

Mary Adelaide Mendelson is the author of Tender Loving Greed, a study of the nursing home industry, published this year by Alfred A. Knopf. Mrs. Mendelson graduated from Radcliffe and received her Masters Degree in Political Science from the University of Michigan. She has been a consultant to the Federation for Community Planning of Cleveland since 1964.

David Hapgood is a journalist. His most recent book is the forthcoming The Screwing of the Average Man, to be published by Doubleday. 
7 HE nursing home industry is 1 highly profitable, having expanded greatly in response to government financing of health care for the elderly and the indigent. Yet, as has been widely documented, most nursing homes fail to provide a decent environment for their charges in spite of government financing. The chronic inability of government at all levels to make increased spending on nursing homes result in better patient care rather than in higher profits for the industry constitutes a dramatic case of the failure of government regulation.

\section{INTRODUCTION}

In the past-a past which seems very distant now-families took care of older people. They lived out their last years in the homes of their grown children. That, too, has changed: older people now live alone as long as they can. However, for many, that time ends long before the end of their lives. Thus, for those who are sick or who are alive but cannot manage alone, the only answer is the nursing home.

Usually, these people cannot pay for the nursing homes they need, because the old are generally poor, as well as sick. People over sixtyfive have less income than younger people; at the same time, they need more health care. Health insurance never covers long term nursing home costs; moreover, for a variety of reasons, the children of old people frequently cannot pay these bills either. This leaves only the government.

Americans have turned over the responsibility for older people-at least for those who are sick and poor-to the state. What happens to old people is decided not by families, but by bureaucracies. The nursing home industry, although privately owned, is a government industry much like the Lockheed Aircraft Corporation. By 1971 twothirds of the million people in nursing homes were supported by government, and more than threequarters of the $\$ 3.5$ billion income of nursing homes was public money.

Public money began flooding the health-care system, including nursing homes, after the 1965 adoption of Medicare and Medicaid. Medicare-title XVIII of the Social Security Act-provided federal financing for up to one hundred days, following hospitalization, in a nursing home. Medicaid-title XIX - which is financed jointly by the federal and respective state governments, pays for an unlimited nursing home stay.

These two acts set off a series of profound changes in nursing homes. In the years after Medicare and Medicaid, health-care prices, including those for nursing homes, went up much faster than the general price level. The mode of operation of the new health-care programs guaranteed excess profits but no benefit to the patientespecially in the case of the nursing home industry. Having taken on the responsibility for sick and poor older Americans, the government has nevertheless failed to exercise the will to ensure the proper carrying out of this responsibility by the institutions to which the old have been entrusted, although there is theoretically an elaborate regulation network to cover both Medicaid and Medicare.

\section{How MEDICAID WorKS}

Medicaid-by far the biggest source of money for nursing homes, because it has no time limit-is 
regulated mainly by the states. Each state, usually through its health department, licenses and inspects nursing homes which accept Medicaid patients. The state inspector decides whether the home is meeting state and federal standards. Also, while Medicaid was intended for the medically indigent-that is, those who cannot afford the care they need-each state decides who is eligible for Medicaid. The income limit varies from state to state and can be somewhat higher than the income limit for welfare. In this system the local welfare caseworker plays an essential part. The caseworker decides whether an applicant is eligible for Medicaid and, if the applicant has some resources-Social Security, in most cases-how much more Medicaid should pay the nursing home for his care. Most importantly, it is the caseworker who usually chooses the nursing home for the Medicaid patient. Thus, the nursing home operator is dependent on the inspector-who could close his home for violations and on the caseworker-who can either guarantee or close off his supply of patients. It is in these relationships that the corruption and indifference of nursing home regulators are most painfully evident.

The states also decide the rates which nursing homes are to be paid for Medicaid patients. Generally, there are two ways of paying the Medicaid bill: (1) flat rate, whereby the nursing home directly receives a set fee per patient per day and (2) cost plus, whereby the nursing home is reimbursed for its costs, plus a "reasonable" profit. Washington's role is mainly confined to paying the federal share of the cost, which ranges from 50 to 80 percent depending on the state. Medicare, which pays for about 4 percent of the nursing home population, operates entirely on federal money and the cost-plus approach.

These, however, are not the only ways in which federal money reaches the nursing home. If a patient gets Social Security, his Medicaid bill is reduced by that amount. The Veterans Administration (VA) also pays nursing homes for the care of some patients coming from VA hospitals.

The advent of Medicaid and Medicare was a clear signal to those seeking a fast way to make money. Those businessmen and hustlers already in the industry saw the new money as a way to expand their operations and their profits. The industry expanded, and prices went up. The patients suffered, not so much because anyone set out to make them suffer-although that happens, too-but because lack of effective controls resulted in lack of incentives for improving patient care. If anything, the operators of nursing homes were motivated to do exactly the opposite: much of the increased profits could come out of the hide of the patient.

Flat rate Medicaid money is the most profitable to the operator and the hardest on the patient. If the government will pay, say, $\$ 14$ a day per patient, the way to make money is obviously to cut daily costs as far below $\$ 14$ as one can. Some costs, such as real estate taxes and interest, cannot be cut. Thus, costs which can be lowered are those incurred by patient care, and that is where the operators cut corners.

First of all, one can buy cheap food in the smallest possible amounts. In the 1970s operators were found who fed patients on less than $\$ 1.00$ a day; one, in Chicago in 1970, managed to feed his patients on $\$ .78$ a day. Not 
surprisingly, many nursing home patients are emaciated.

One can also cut corners on staff: hire a cheaper practical nurse rather than a registered nurse. One can pay the lowest rate for aides by hiring people who cannot hold a job anywhere else. The patients will suffer-for example, incompetent aides, who seem to be taking out their own inadequacies on the people in their charge, are responsible for much of the brutality in nursing homes-but the profits will go up.

These variable costs are that part of the nursing home operation which is the most subject to governmental regulation-at least on paper. Thus, if the operator can cut these costs, it is because the regulators let him get away with it. From the point of view of the operator, it is cheaper to buy off an inspector or caseworker than to pay the cost of decent patient care.

The game of profit is played differently if the nursing home is not paid a flat rate per patient per day, but is reimbursed for its costs. This is the method used by Medicare and also by Medicaid in some states. In this situation there is no incentive to cut costs, since the costs are passed on to the government; the operator's opportunity to increase profits lies in padding his bills. This swindle is made easy by the fact that the government rarely conducts any effective audit of nursing home bills.

\section{ANCILlary Fraud}

The extra-or ancillary-services which the government purchases for nursing home patients provide a rich field for exploitation. Here, the opportunity for profit lies in the operator's rela- tionship with people for whose goods and services the government pays. Although the operator does not collect the money himself-it is paid directly to the supplier-he has the power to determine who will collect, since he chooses the suppliers and decides how much they are to deliver. Thus, the operator decides which pharmacist will get the considerable drug business his home provides. Since he has no motive to demand a lower price-the government is paying-it is common practice for him to demand a kickback from the pharmacist he chose. If the operator is at all unscrupulous, he has other opportunities to make extra money. $\mathrm{He}$ can order expensive brandname drugs and let the pharmacist fill the prescription with much cheaper generic drugs which are identical to the brand-name drugs; the government pays the higher price and the operator and pharmacist split the difference. Or, he can order drugs in unnecessarily large quantities. Or-most simply and with the greatest profit-they can bill the government for the drugs which are never delivered at all.

The operator also chooses the physicians who will be paid for attending those patients who do not have their own doctors. If both are unscrupulous, the result is the gang visit, as it is known in the trade -that is, the physician whips through the nursing home in a couple of hours, glancing at only the most urgent cases, and later bills the government as if he had given individual attention to each patient. In its investigation of Ohio nursing homes the General Accounting Office (GAO) found not a few examples of such gang visits. One doctor billed the government for 487 visits within a sixteen-day 
period, including 90 on one day and 86 on another. A podiatrist put in for 750 visits, including 32 on one Sunday. All these doctors were also handling their usual load of non-Medicaid patients. Physicians and other health professionals can also order, at government expense, goods and services which the patients clearly do not need.

Such swindles may seem petty when viewed individually. However, in sum, all those nickels and dimes add up to many millions, if not billions, of dollars a year. Nursing home operators and their collaborators can engage in these deals safely, because there is little risk of being caught and, even if caught, virtually no risk of being punished. Neither the GAO nor any other investigating agency has looked at more than a small fraction of the records. Yet, if the pattern found so far is typical of the industry-and there is every reason to believe it is - then there are literally millions of frauds waiting to be uncovered.

The nursing home operator and his partners are not punished, except in rare and extreme cases. Typically, if a government auditor catches the operator and, say, the doctor cutting a little extra on the side, all the auditor does is force them to give back the money. The case is not sent over to the district attorney for criminal prosecution, nor is any move made to revoke the operator's license. The operator's explanation-usually "clerical error"-is allowed to stand. This happens even when the same operators are caught time and time again in the same types of fraud. While the explanations begin to wear thin, no attempt is made to deter the operators from trying again. There is, indeed, no reason for them not to try again.

\section{High Level Swindles}

Beyond these types of swindles-which are known to those who follow the Medicaid scandals - is a quite different kind of fraud, cloaked in secrecy and complexity, unknown to the public and even to many nursing home critics. Frauds at this level are the most sophisticated method for hustling the government for nursing home money. The opportunity, once perceived, has drawn into the nursing home field con men and manipulators whose skills and imagination put them in a class apart from those operators whose stealing is limited to kickbacks from pharmacies and doctors. Few of these newcomers have any experience in nursing homes or in any other aspect of the health field. All they know is how to make money, and they sense that the nursing home is a good place to use their talent.

The basic strategy of these speculators is to manipulate the ownership and mortgaging of those nursing homes which receive guaranteed government income in order to extract the most revenue and to pay back the least amount in the form of income taxes. Among the costs of operating a nursing home are the costs of ownership - that is, the amount paid out in either rent or mortgage interest payments - costs which are reimbursed by the government when it pays for its Medicaid and Medicare patients. The higher the cost of ownership, the more the government pays. Of course, the government payment does not stay with the operator; it goes on to the owner-if the operator pays 
rent-or to the mortgage holderif the operator is also the owner. Thus, higher ownership costs seem to benefit someone other than the operator.

The solution is to make the owner appear to be someone other than the operator, while in fact the same people are collecting at both ends. If, for example, a man owns a nursing home, he may "sell" it to someone who turns out to be a friend or a relative, then "rent" it back at a rental which requires the government to increase its payments. He splits the profit between himself as operator and himself, in different guise, as owner. Or, alternatively, he may build a nursing home and rent it, at a very high figure, to a "nonprofit" corporation he or his friends have created. The government will pay more to that corporation, because of the high rental, than the amount-which would have been based on the cost of building the home-it would have paid to him directly. The extra payment, of course, comes back to the owner in the form of the extra high rent. He may sell the home at an inflated price to some associates, who use the price as a basis for getting higher payments from the government. In each of these maneuvers the amount being received has been increased by increasing the apparent cost of ownership. The same principle can be applied to other costs. One can drive up the costs of supplies by paying more than market price to suppliers, who turn out to be either one's associates or oneself under another corporate name.

The method varies somewhat according to the way the government pays off. In a straight costreimbursement situation - all Medicare patients and in some states
Medicaid patients, also-the payoff is immediate, for the government pays exactly the apparent cost, plus a percentage of profit. If the cost is raised, the payment goes up automatically. In the case of homes paid on flat rate system, the payoff is not so quick. Here, the nursing home industry must use the higher costs of ownership as a basis for lobbying the state for an increase in the flat rate. In the almost annual bouts of lobbying over the rates, the nursing home representatives use those costs as apparent hard evidence that they need more money. Unless the state looks behind the figures, they will appear to be convincing evidence; since, in fact, the states usually take the industry's figures and simply shave them a little, the contrived cost increases eventually produce the desired effect.

A universal reason for such complex transactions is to hide the incredibly high profits made by the nursing home industry. For one thing, too visible profits might undercut the poormouthing which accompanies the industry's pleas for higher rates. In practice, these profits do not seem to matter. For example, in the late sixties nursing homes were successfully lobbying for higher rates at the same time that stock speculators were pronouncing the industry to be the hottest thing on Wall Street.

In a broader sense, this industry - as does any other - spends much of its inventive skill in trying to minimize the amount of income tax it has to pay. When one makes as much money as most nursing homes do, that can be a problem. Shifts of ownership can help. If, for example, one sells the home at an inflated figure and then rents it back, the profit can be taken 
as capital gains instead of regular income, and the tax will be lower.

Shifting costs to the nursing home is a way of shifting profits out, into another corporation set up for that purpose. Such an arrangement may permit one to diffuse the profits-perhaps by putting family on the payroll-before Internal Revenue can get at them. The nursing home chains, which have the best accountants, have pioneered this territory. One chain has at least five subsidiaries from which it buys goods and services.

It should be emphasized that many of these tax-avoidance ploys are legal. Legal or not, however, the taxpayer bears the cost of the nursing homes' excessive profits.

Manipulating mortgages is another aspect of profit making in the nursing home industry. Despite the many protestations to the contrary, there is no safer risk than the nursing home. With guaranteed government revenue, with a growing elderly population and with high occupancy rate, there is, as one Wall Street expert said, "no way" not to make money in this business. What could be a better bet than to lend-or borrowmoney against guaranteed government revenue? In this manner many shoestring operators have gotten their start. If they can scrape together enough in loans-often from the original owner-for the down payment to buy a home, they can get a first mortgage on the home at the normal interest rate of 6 to 8 percent. That home can subsequently be used as collateral for second and third mortgages at much higher rates of interest. Although these interest payments can then be used as the basis for higher reimbursement, there is, in fact, no requirement that the money from such second and third mortgages be used for the nursing home itself.

Government revenue, in effect, endorses pyramiding and other dubious business practices. The sure supply of governmentsupported patients allows nursing home owners to take risks which other kinds of businesses cannot afford. Not only that: by underwriting manipulations that artificially increase nursing home costs, the government also guarantees unnecessary increases in the rates it pays for patient care. That, too, has a double effect, for each increase in rates drives onto Medicaid people who were able to pay their own way when the rates were lower. Higher rates thus increase the number of patients supported by government, as well as the rate paid for each patient. In these many ways government policy-or lack of policy-has served to enrich nursing home owners at the expense of both taxpayers and patients.

\section{TOLERANT REgUlators}

This situation-in which ever larger amounts of government money disappear, ever higher profits are made and patient care is not at all improved-is tolerated by governmental regulators at all levels. The problem is not a lack of regulations; the industry is festooned with rules which theoretically determine its conduct. However, the regulations are not enforced.

Year after year the rules laid down by government are disobeyed. Thus, reformers who demand better regulations miss the point, and in a way that is dangerously deceptive. It is relatively easy for reformers to achieve a 
change in the regulations and then to go home believing that they have made a lasting change in the way the nursing home industry actually operates.

The nursing home industry has won for itself a large degree of immunity from accountability to those who finance it. How this has been done is not entirely clear, for there is no comprehensive information on nursing home lobbying-or, for that matter, on its profits or on its ownership. Enough is known, however, to suggest why the industry finds government such an easy target.

The state is the crucial level of government. The Medicaid reimbursement rate, by far the most important source of revenue in the industry, is set by the state legislatures. Moreover, nursing home inspection is generally a state function.

The industry seems to be influential in the state legislatures. Since nursing homes are widely dispersed, most legislators have at least one in their district. Owners and operators show up regularly as campaign contributors. Although the amounts one hears about- $\$ 500$ or $\$ 1,000$-are paltry when compared to the amounts which change hands in presidential elections, that kind of money can buy considerable influence in a state legislature, especially in the absence of countervailing pressure.

The absence of such pressures largely results from the way Medicaid is financed. Although the state legislature sets the Medicaid rate, the federal government pays from 50 to 80 percent of the bill. So, a state legislator considering competing demands for money knows that half, or more than half, of what he votes for nursing homes will not have to be paid by state taxes: a dollar for the nursing homes only costs the state from 20 to 50 cents. Thus, nursing home lobbying can pay high returns.

In a recent speech John Timothy. McCormack, an Ohio state representative from Cleveland, set forth his view of the relative pressures on state legislators:

The nursing home industry is very well organized, is well represented in terms of lobbyists in the Legislature ... There is not a high degree of interest relative to nursing homes in the Legislature. There is not a high degree of knowledge and there is very little public attention focussed on the problem.... The only voice that has come through clearly is that of the nursing home industry. . . . The industry, in fact, plays the dominant role in the establishment of rates that are set by the Legislature. Now that undoubtedly means that the best way to determine what the rates will be for the nursing homes [is] to look at the most recent edition of the nursing home industry magazine, [see] which Senator is featured on the cover with his biographical statement and given credit for saving the industry. Determine how much power that Senator has and you can probably determine just how those rates might be established in the Legislature.

In Washington the federal agency most concerned with nursing homes is the Department of Health, Education and Welfare (HEW). It has shown little effective interest in the industry, and its consistent policy of secrecy has kept the public and Congress in the dark about nursing home realities. It is mainly because of HEW that the basic facts about nursing home ownership and profits remain unknown. When Congress mandated HEW to find out who owns nursing homes, the agency evaded the legislative in- 
tent by permitting empty replies, such as the statement that a given nursing home's owner was a corporation. As for profits, HEW has simply never tried to find out, although it would seem impossible to evaluate nursing home reimbursement rates without knowing what profits the industry is making.

The most blatant form of secrecy practiced by HEW involves the reports of nursing home inspections. If there is any single piece of information to which the public should be entitled, it is the inspector's current report on a nursing home. Any member of the public-not to mention the taxpayers, who may be interested in what the home is doing with their money-should have the right to see the reports before choosing a nursing home. The only effect of hiding that information is to protect both the operator who runs a bad home and the inspector who lets him get away with it.

That fig leaf was at last ripped-or so it seemed-from the industry in 1972 by the courts: a successful suit by a newsman, Mal Schechter, of the magazine Hospital Practice, forced HEW to grant access to Medicare inspection reports. The bureaucracy resisted stubbornly. HEW interpreted its defeat in the courts to mean only that Schechter himself could have access to the eight reports on which he had brought his suit, not that the public at large had any right to see Medicare inspection reports.

In 1972 the Congress adopted legislation requiring HEW to make public both Medicare and Medicaid reports. This law did not, however, settle the issue because, as always, the agency-not Congress - is to implement the law. HEW was far from giving up the struggle to keep the public in the dark. As of this writing, the regulations proposed by HEW would only make public an extract from the inspector's report, not the full report. Furthermore, that extract in the case of Medicare could only be seen-not ordered by mail or phone-at a Social Security office. In the case of Medicaid one can inspect the extract at the local welfare office. Thus, a member of the public can see those extracts, if he is willing to find his way to the proper office, no matter how far, and if - the biggest if of all-he happens to find out that he is entitled to the information. No one is broadcasting the news.

The distance between HEW's policy of secrecy and a policy of protecting the public interest can be most clearly measured by contrasting what the agency did with what it has not done. At no time did HEW take the simple, effective step of ordering operators of all nursing homes receiving federal money to post the latest inspection report prominently in the home, with copies available to potential applicants. Such a procedure would make available to those most concerned the inspector's judgment on the home and would also enable someone reading the posted report to contrast it with the reality around him.

Much of government's role in overseeing the spending of its money has been, in effect, abdicated to the health industry. This has happened in the choice of what are called fiscal intermediaries. When Medicaid and Medicare were created, it was obvious that they would cause a flood of paper work in the form of millions of individual bills being presented to government for payment. Medicare 
and, in some states, Medicaid retained existing organizations to process the papers - that is, to audit and to pay the individual bills for the government. This lightened the government work load, but it also removed from government much of the responsibility of the newly created programs.

The organizations selected as fiscal intermediaries in most parts of the country are Blue Cross and its sister organization, Blue Shield. Blue Cross is itself part of the health industry. Controlled by hospitals and doctors, it was founded to help hospitals collect their bills. It has always defended the interests of the health industry in conflicts with those-whether consumers or government-who pay the bills. Nursing homes are first cousins to hospitals; their financial practices are similar, and so are the ways in which their costs are unnecessarily inflated and passed on to government. Therefore, when government chose Blue Cross as a fiscal intermediary, to a large extent it was allowing the health industry to regulate itself.

Some of those who made nursing home policy for HEW have had direct ties to the industry. For some years the chairman of HEW's National Advisory Council on Nursing Home Administration was Harold Baumgarten. Baumgarten was president of one corporation operating a nursing home and director of another-facts never mentioned in the extensive biographical material about him which HEW published. The HEW staff man for that Council was Charles A. Cubbler; he was a director of the nursing home corporation of which Baumgarten was president. When HEW was instructed by Congress to draft standards nursing homes would have to meet to qualify for Medicaid-a question of crucial importance to the industry-the agency hired Harold Smith as a consultant to write the standards. Smith was not only a former official of the Louisiana Nursing Home Association, but was also serving as chairman of the Legislative Committee of the American Nursing Home Association at the time he was hired by HEW.

\section{Why Regulation FaILS}

Such examples should not be read to mean that personal connections between the industry and its regulators, nor the occasional instances of outright corruption, are the only explanation for the failure of government regulators. There are other, less dramatic, factors involved. One is the familiar phenomenon of bureaucratic lassitude. If the typical nursing home regulator is to do his job well, he must work hard and suffer recurring conflicts with those whom he regulates. He must do so, moreover, with little support; in fact, he is under constant pressure to go easy on the nursing homes and under little or no pressure to do the opposite. Being human, inspectors usually succumb to the strongest pressures.

The difficult, small-scale nature of nursing home regulation is another important factor. In the regulation of this industry there are no great decisive moments on which public attention can focus, no equivalents of the congressional votes on the $\mathrm{ABM}$ or the Lockheed loan. Instead, the action takes place in 23,000 nursing homes across the country, and the failure of the regulators is not found in dramatic actions, but in numberless small 
duties left undone. Those lobbying for nursing home reform cannot mobilize themselves for a single pitched battle; they must be prepared to exert continuing pressure over many years and in many places.

The Nixon administration's nursing home reform program provides an illustration. In August, 1971, the president announced an eight-point program to deal with the problems of nursing homes. Of the eight points, the most important was the promise to cut off Medicare and Medicaid funds to nursing homes which did not meet "reasonable standards." By mid-1973 it became obvious that little had improved, in spite of the president's announced intent: only one of every two hundred patients in a Medicaideligible home was actually moved to another-presumably betterhome. Furthermore, for two years demands for reform could be warded off with a reference to the de- cisive actions which were in the making.

Lack of effective public pressure is, of course, the most basic reason for the failure of nursing home regulation. The primary victimsthe patients - are unable to make effective protest against their lot. Most patients do not have concerned relatives; relatives who are concerned have not constituted an effective lobby. The financial victims of the nursing homes-the taxpayers - are no more effectively organized to combat this form of waste than they are any other. Older people-strong lobbyists on some issues - have not had much impact on nursing home policy. One possible reason is that older people have more reason than most to fear an institution in which they may soon find themselves. Most of all, the lack of public pressure for nursing home reform may simply be another expression of our turning away from the realities of old age. 